\title{
บUsisersily
}

\section{Patients with long bone fracture have altered Caveolin-1 expression in their peripheral blood mononuclear cells}

Tang, PF., Burke, GA., Li, G., \& Wang, Y. (2009). Patients with long bone fracture have altered Caveolin-1 expression in their peripheral blood mononuclear cells. Archives of Orthopaedic and Trauma Surgery, 129(9), 1287-1292. https://doi.org/10.1007/s00402-008-0776-6

Link to publication record in Ulster University Research Portal

\section{Published in:}

Archives of Orthopaedic and Trauma Surgery

Publication Status:

Published (in print/issue): 01/09/2009

DOI:

10.1007/s00402-008-0776-6

\section{Document Version}

Publisher's PDF, also known as Version of record

\section{General rights}

Copyright for the publications made accessible via Ulster University's Research Portal is retained by the author(s) and / or other copyright owners and it is a condition of accessing these publications that users recognise and abide by the legal requirements associated with these rights.

\section{Take down policy}

The Research Portal is Ulster University's institutional repository that provides access to Ulster's research outputs. Every effort has been made to ensure that content in the Research Portal does not infringe any person's rights, or applicable UK laws. If you discover content in the Research Portal that you believe breaches copyright or violates any law, please contact pure-support@ulster.ac.uk. 


\title{
Patients with long bone fracture have altered Caveolin-1 expression in their peripheral blood mononuclear cells
}

\author{
Pei-Fu Tang • George A. Burke • Gang Li • Yan Wang
}

Received: 11 May 2008

(C) Springer-Verlag 2008

\begin{abstract}
Introduction Fracture triggers a cascade of systemic and local responses including inflammatory mediator signaling, chemotaxis, osteogenic cell recruitment, differentiation and proliferation at the fracture site. Early signaling between immune cells and repair cells in fracture repair is not well understood. Caveolin-1, a 21-24 kDa membrane protein plays key roles in transmembrane signaling. This study was to investigate the expression of caveolin-1 in human peripheral blood mononuclear cells (PBMNCs) following long bone fracture.

Methods PBMNCs were obtained from healthy volunteers or fracture patients at three time points following fracture by density-gradient-centrifugation procedure. Caveolin-1 gene expression and protein characterization was examined by semi-quantitative RT-PCR, immunocytochemistry and Western blot analysis.
\end{abstract}

P.-F. Tang · Y. Wang $(\bowtie)$

Department of Orthopaedic Surgery,

General Hospital of Chinese People's Liberation Army,

28 Fu-Xing Road, 100853 Beijing, People's Republic of China

e-mail: yanwang301@yahoo.com

G. A. Burke · G. Li

Department of Orthopaedic Surgery, School of Medicine, Dentistry and Biomedical Sciences, Queen's University Belfast, 97 Lisburn Road, Belfast BT9 7B, UK

\section{G. Li}

CUHK-WHO Collaborating Centre for Sports Medicine and Health Promotion, Department of Orthopaedics and Traumatology, The Chinese University Hong Kong, Clinical Sciences Building, Prince of Wales Hospital, Shatin, Hong Kong, People's Republic of China e-mail: G.Li@qub.ac.uk
Results Caveolin-1 mRNA and protein was expressed at low levels in the PBMNCs of non-fracture samples. In contrast, caveolin-1 expression was greatly increased in the PBMNCs of fracture patients 9-12 days and reduced at 1621 days following long bone fracture.

Conclusion The identification of caveolin-1 in PBMNCs and osteoblasts makes this cellular domain a new focus for further investigation. We speculate that caveolin-1 expression in PBMNCs and osteoblasts play an important role in signal transduction during the early stages of fracture healing and may be an indicator for normal or abnormal fracture repair.

Keywords Caveolin-1 C Caveolae $\cdot$ Mononuclear cells . Blood $\cdot$ Fracture healing

\section{Introduction}

Caveolae are 50-100 nm membrane micro-invaginations that are associated with a sub-compartment of the plasma membrane in a wide variety of cells [29]. Four homologous but distinct caveolin proteins have been defined as caveolin- $1 \alpha$ and $1 \beta, 2$ and 3 , which have different but overlapping tissue distributions [23]. Caveolin-1 is the membrane protein that forms part of the caveolae [17]. Caveolin-1 mRNA and protein expression is the highest in adipocytes, endothelial cells, smooth muscle cells and fibroblasts $[10,16]$. Much like the Toll-like family of receptors involved in innate immunity, the caveolin gene family is both structurally and functionally conserved [14] suggesting an essential role of caveolins in organizing and concentrating signaling molecules.

The main functions of caveolae are transcytosis of both large and small molecules across cell membrane [1]; signaling 
processing and transduction [6, 26]; sites of nitric oxide (NO) production and endothelial nitric oxide synthase (eNOS) [7, 8, 20, 28]. Diseases such as cancer [30], muscular dystrophy [24] and diabetes [13] appear to relegate to the caveolae membrane system. Evidence for caveolin expression in macrophages and peripheral blood mononuclear cells (PBMNCs) remains controversial, some groups reporting the absence of caveolins in neuronal and blood cells $[5,11]$, while others confirmed the presence of caveolin-1 in macrophages [9, 15] and dendritic cells [31]. A recent report suggested that caveolin-1 expression could be induced in blood cells during certain states of cell activation or by some stimuli [12].

Fracture repair is a complex physiological process involving both local and systemic factors during which bone shows a remarkable ability to mount a repair process that not only restores the mechanical integrity but also anatomical configuration. Following the initial injury, there is an accurate phase of hematoma formation and inflammation that may involve transient systemic responses such as altered immune functions and systemic recruitment of repair cells through circulation. It is well recognized that failed initial inflammatory and immune response may result in fracture non-union or delayed union. We hypothesized that the immune responses lead to repair process may be linked through the changes of expressions of caveolins. As stated above, caveolins are the main signaling components for various receptors in the cell membrane, and caveolin-1 may be an important cellular regulatory protein in cellular signaling in various diseases situations $[13,24,30]$ and plays an important role in regulating fracture healing that has never been discovered. Thus, the purpose of this study is to exam caveolin-1 expression in PBMNCs at the mRNA and the protein level in the patients having long bone fracture and to compare that with healthy individuals.

\section{Methods}

\section{Extraction of RNA from PBMNCs}

About $15 \mathrm{ml}$ of peripheral blood was taken from healthy donors at one time point and from 7 patients with tibial or femoral fracture at 3 time points following fracture, days 1$3,9-12$ and 16-21. Patients were randomly selected, with mean age of 31 , and presented with no known metabolic bone disease and were not under long-term medication. All samples were taken with patient's consent and local hospital's ethical approval.

For isolating PBMNCs, $15 \mathrm{ml}$ blood was first diluted twofold in sterile $0.9 \%$ saline, then two parts of the diluted blood was layered over one part of Lymphoprep ${ }^{\mathrm{TM}}$ (Nycomeb Amersham, Oslo, Norway) and centrifuged at
$500 \mathrm{~g}$ for $30 \mathrm{~min}$ at room temperature. The mononuclear layer was aspirated, and washed twice in $10 \mathrm{ml}$ of ice-cold red cell lysis buffer $\left(0.144 \mathrm{M} \mathrm{NH}_{4} \mathrm{Cl}, 1 \mathrm{mM} \mathrm{NaHCO}{ }_{3}\right)$ to remove any remaining red cells. The mononuclear cells were then washed twice in sterile saline solution, centrifuged at $600 \mathrm{~g}$ for $10 \mathrm{~min}$ at $4{ }^{\circ} \mathrm{C}$ and the cell pellet lysed in $3 \mathrm{ml}$ of guanidine isothiocyanate buffer with $1 \% \beta$-mercaptoethanol and vortexed briefly. RNA was isolated using the phenol chloroform method outlined by Sacchi and Chomczynski [2]. RNA integrity was verified by ethidium bromide staining of $28 \mathrm{~S}$ and $18 \mathrm{~S}$ ribosomal RNAs.

Preparation of human osteoblasts

Human bone-derived osteoblastic cells (HOB) were cultured from trabecular bone explants obtained at the time of total hip arthroplasty. The bone fragments were washed in sterile saline to remove fat and blood cells. Small bone chips (approximately $5 \times 5 \times 5 \mathrm{~mm}$ ) were then placed in T-75 flasks, each containing $15 \mathrm{ml}$ DMEM (Sigma, Pole, UK) supplemented with $10 \%$ heat-inactivated fetal calf serum (FCS), penicillin $(100 \mathrm{U} / \mathrm{ml})$, streptomycin $(50 \mu \mathrm{g} /$ $\mathrm{ml})$ and amphotericin B $(2.5 \mu \mathrm{g} / \mathrm{ml})$, and cultured at $37^{\circ} \mathrm{C}$ in a $5 \% \mathrm{CO}_{2}$ atmosphere. The first medium change was made at day 8 and thereafter the medium was changed every five days until the flask became confluent around weeks $4-5$. All cells used in this study were between passages $2-4$.

\section{Cell staining and microscopy}

Approximately $20 \%$ of the PBMNCs isolated from each sample were spun onto glass slides by cytospin preparation using a Cytospin 3 centrifugator (Shandon, USA). After centrifugation, the slides were fixed in $95 \%$ ethanol for $10 \mathrm{~min}$ and stored for future use. HOBs were harvested from the flasks by Trypsin/EDTA treatment, and the separated cells were seeded in 4-well chamber slides (approximately $5 \times 10^{4}$ cells/well) and cultured for 3 days. The slides were then fixed in $4 \%$ freshly prepared paraformadehyde for $10 \mathrm{~min}$ at room temperature and stored in PBS for Immunocytochemical analysis.

For immunocytochemistry, the cell slides were washed in PBS and incubated with $1 \%$ BSA in PBS for $10 \mathrm{~min}$. Mouse anti-human caveolin-1 antibody (Becton-Dickinson, UK) diluted in PBS at a concentration of $5 \mu \mathrm{g} / \mathrm{ml}$ was applied to the slides and incubated for $1 \mathrm{~h}$ at room temperature. Following washing in PBS $(3 \times 5 \mathrm{~min})$, the slides were then incubated with rabbit anti-mouse FITC conjugated secondary antibody for $45 \mathrm{~min}$ in a darkened chamber. Slides were then washed in PBS $(3 \times 5 \mathrm{~min})$ to remove the secondary antibody. To gain some visualization of the nuclei some of the slides were incubated in $1.0 \mathrm{mg} / \mathrm{ml}$ 
propidium iodide for $2 \mathrm{~min}$ before rinsing in PBS and mounted in mounting media (50\% PBS and 50\% glycerol, $0.1 \% p$-phenylenediamine, $\mathrm{pH}$ 8.0). Slides were viewed under a fluorescence microscope (Olympus, UK). Cells were also examined using a non-fluorescence disclosure technique, where primary antibody was localized with the horse radish peroxidase conjugated secondary antibody and peroxidase substrate 3,3'-di-amino-benzidine (DAB), counterstained with hematoxylin and mounted.

\section{Western blotting}

PBMNCs were collected from three fracture patients at three time-points following fracture and one time points from three non-fracture controls. HOBs in culture were used as positive controls. Cells were lysed by the addition of RIPA lysis buffer (50 mM Tris-HCl, pH 7.4, $1 \%$ NP-40, $0.25 \%$ Na-deoxycholate, $150 \mathrm{mM} \mathrm{NaCl}, 1 \mathrm{mM}$ EDTA, $1 \mathrm{mM}$ PMSF, $1 \mathrm{mg} / \mathrm{ml}$ each of aprotinin, leupeptin, pepstatin, $1 \mathrm{mM} \mathrm{Na} \mathrm{VO}_{4}, 1 \mathrm{mM} \mathrm{NaF}$ ) for $20 \mathrm{~min}$ on ice. Insoluble materials were removed by centrifugation at $13,000 \mathrm{rpm}$ for $10 \mathrm{~min}$ at $4^{\circ} \mathrm{C}$. The supernatants were collected and the protein concentrations determined using the BCA protein estimation kit (Pierce, USA). An identical amount of protein $(10 \mu \mathrm{g})$ from each lysate was subjected to $10 \%$ sodium dodecyl sulphate polyacrylamide gel electrophoresis (SDS-PAGE). Proteins were transferred to a nitrocellulose filter and the filter blocked for $2 \mathrm{~h}$ in 5\% nonfat dried milk in TBS (50 mm Tris, $0.15 \mathrm{M} \mathrm{NaCl} \mathrm{pH} \mathrm{7.5)}$ containing $0.1 \%$ Tween-20, washed in TBS and incubated at room temperature for $1 \mathrm{~h}$ in primary antibodies directed against caveolin-1 (Becton Dickinson, UK). The nitrocellulose membranes was then washed in TBS and incubated with the appropriately labeled HRP-conjugated secondary antibody. The enhanced chemiluminescence system (ECL, Amersham, UK) was used for detection of protein bands.

Reverse transcriptase polymerase chain reaction (RT-PCR)

Reverse transcriptase polymerase chain reaction (RT-PCR) was performed for detecting caveolin-1 mRNA in the PBMNC samples obtained. cDNA was produced using the first strand can synthesis kit (Roche, UK). Oligonucleotide primers for caveolin-1 were synthesized according to the available details on the human genome mapping project: forward primer- TAC AAG CCC AAC AAC AAG; reverse primer- ACA GTG AAG GTG GTG AAG for 35 cycles at an annealing temperature of $60^{\circ} \mathrm{C}$. Band analysis of PCR products on agarose gels was conducted using the EDAS 120 software (Kodak Digital Science, UK). At least three separate experiments were performed on each patient sample. RT-PCR was also performed on cDNA obtained from human osteoblasts grown in culture. A housekeeping gene, acidic ribosomal phosphoprotein (ARP), forward primerCGA CCT GGA AGT CCA ACT AC; reverse primerATC TGC TGC ATC TGC TTG was also used.

\section{Results}

Immunocytochemistry of caveolin-1 in PBMNCs and HOBs

Almost all HOBs were strongly positive for caveolin-1, staining was localized on the outer cell membrane with little nuclear staining (Fig. 1a). There was no staining on the negative control without primary antibody (Fig. 1b). In PBMNCs, staining was particularly strong on the plasma membrane and also in the cytoplasm (Fig. 1c). This may correspond to soluble and insoluble forms of caveolin-1, respectively. There was no difference in the immunostaining pattern of caveolin- 1 in the control blood cells and those that were obtained from fracture patients (Fig. 1d).

\section{Western blotting for caveolin-1}

Caveolin-1 expression was not detected in the PBMNCs from the controls, but was detectable in the PBMNCs of patients with fracture (Fig. 2). The expression was weak in the early time-point 1 (day 1-3 post fracture), peaked in the middle time-point (day 9-12 post fracture) and declined at later time point (day 16-21 post fracture) as shown in Fig. 2.

RT-PCR of caveolin-1

RT-PCR results showed the level of caveolin-1 expression varied in patients following fracture (Fig. 3a). Caveolin-1 was not readily or lowly expressed in non-fracture controls, but the level of expression was dramatically increased in patients following fracture and was particularly high in the early stages of fracture healing (days 1-12). However, the level of expression generally reduced around days 16-21 following fracture (Fig. 3a). There was no difference seen on the expression ARP gene in all the samples (Fig. 3a). HOBs were strongly positive for caveolin-1 gene expression (data not shown). Caveolin-1 gene expression was significantly increased in PBMNCs of fracture patients at days 9-12 $(P=0.018)$ than the control and other two time points (Fig. 3b).

\section{Discussion}

The caveolins are increasingly implicated in diverse biological processes such as signal transduction, cellular 
Fig. 1 a HOBs were strongly positive for caveolin-1, staining was localized on the outer cell membrane with little nuclear staining. b There was no staining on the control. c In PBMNCs, staining was particularly strong on the plasma membrane. $\mathbf{d}$ The pattern of the staining of caveolin-1 using HRP immunostaining method was similar to that seen in using fluorescence immunostaining method
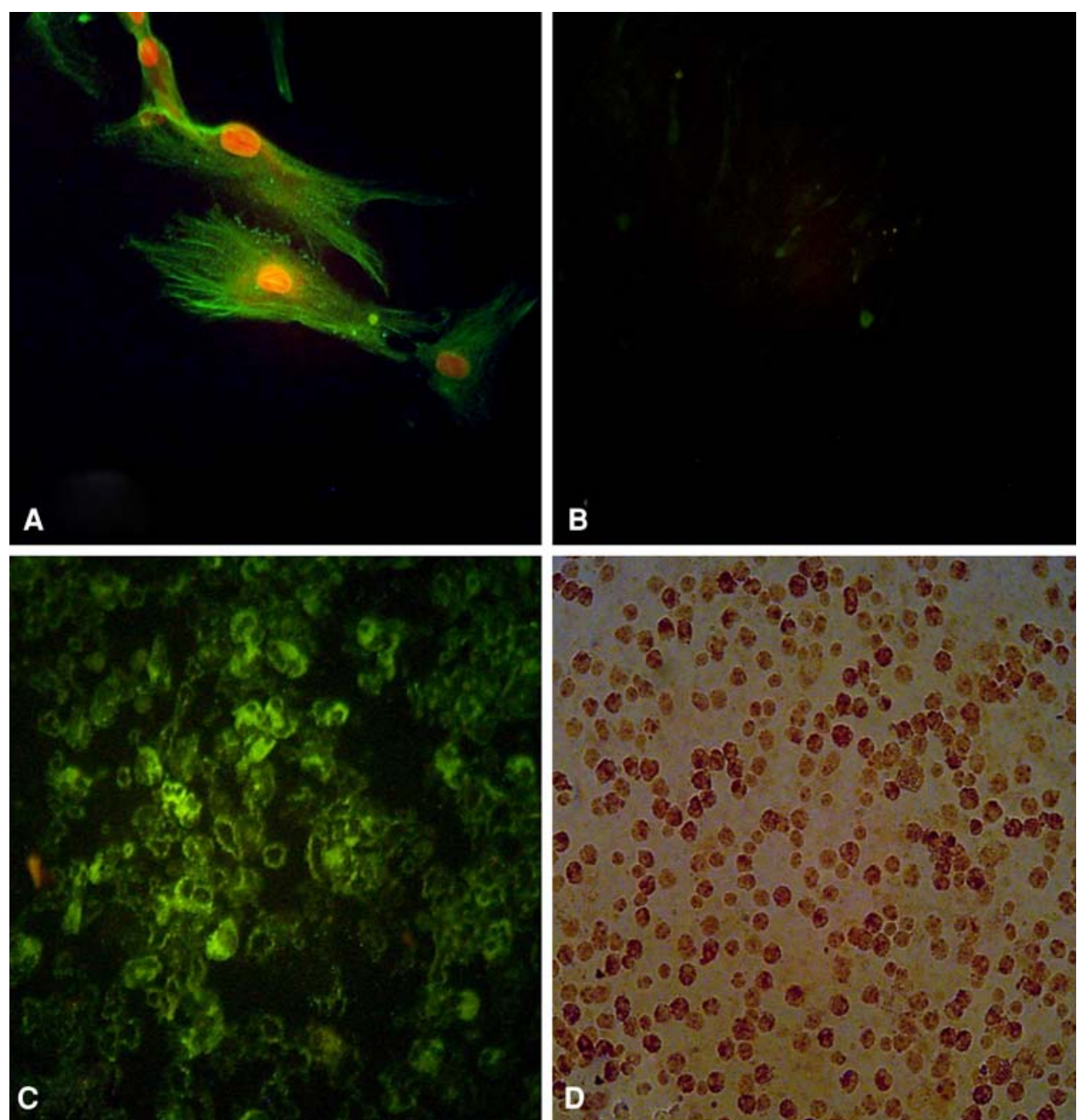

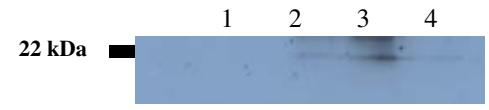

Lane No. Sample

Control no fracture

Fracture patient time point 1

Fracture patient time point 2

Fracture patient time point 3

Fig. 2 Caveolin, a 22-kDa structural component of caveolae was present in PBMNC lysates from fracture patients. Caveolin-1 expression was not detected in the PBMNCs from the controls with no fracture (Lane 1), but was detectable in the PBMNCs of patients following fracture (Lanes 2-4). The expression was peaked in the middle time-point, day 9-12 post fracture (Lane 3) and declined at later time points, day 16-21 post fracture (Lane 4)

transport, cell differentiation and apoptosis [19-21, 25]. The presence of many receptors and signal transduction molecules in caveolae suggests a key role for caveolae in signal transduction [18].

A number of early investigators have shown the lack of any caveolin isoforms in human peripheral blood cells. The absence of caveolins was demonstrated in lymphocytes [5] and platelets [4]. A recent report by Sengeløv et al. [27] showed absence of the protein in neutrophils. Studies on human blood cell lines, including the myeloid leukemic cell line, erythroid cell lines [22], lymphoid cell lines [5], demonstrated the absence of caveolin-1 in these cells, suggesting the general lack of caveolin-1 in human blood cells. However, Yan et al. [32] reported the presence of caveolin1 in neutrophils by Western blotting, and new research indicated that some human T-cell lines express caveolin-1 as assessed by immunostaining and Western blotting [12] Western blotting and RT-PCR results presented in the current study would support the previous findings that caveolin-1 is rare in non-fracture control mononuclear cells. However, following a stimulus such as fracture, the increased caveolin-1 gene expression supports the findings of Hatanaka et al. [12] who suggested that the presence of caveolin-1 in the PBMNCs in a disease stimulated state. In the present study, caveolin-1 expression found in normal mononuclear cells by ICC may represent a significant finding that caveolin-1 may be a normal constituent of the 


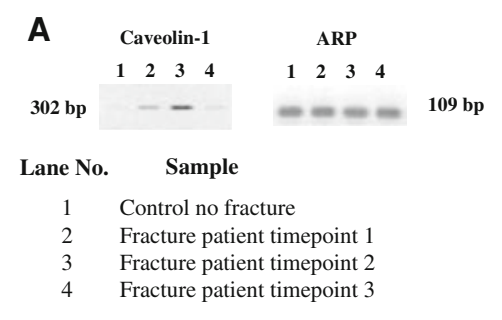

B Caveolin-1 mRNA expression in PBMCs

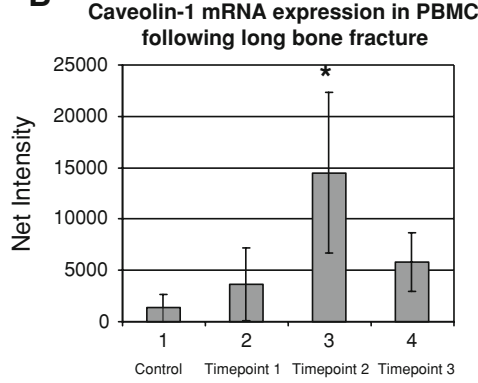

Fig. 3 a RT-PCR results showed the level of caveolin-1 expression in patients following fracture. Caveolin-1 was not expressed in non-fracture controls (lane 1), but the level of expression was increased following fracture, particularly high in the early stages of fracture healing (days 1-12) (lanes 2-3). The level of expression was reduced around 16-21 days post fracture (lane 4). There was no difference seen in the expression ARP gene in all the samples. b Caveolin-1 gene expression was statistically higher in the PBMNCs of fracture patients at time point 2 , days $9-12$ post fracture $(* P=0.018, t$ test) compared to the control and other two time points

PBMNCs and it can be up-regulated in response to stimuli such as long bone fracture.

Caveolin-1 is highly expressed in terminally differentiated mesenchymal stem cells (MSCs) including adipocytes, endothelial cells, and smooth muscle cells. MSCs are also known to be present in the blood of normal individuals [3, 33 ] and we cannot exclude the possibility that in long bone fracture patients, the number of circulating MSCs is increased. This was supported by the finding of Cilloni et al. [3] who reported that bone surgery might act as a stimulus for mobilization of MSCs in peripheral blood. The increased expression of caveolin-1 in the PBMNCs of long bone fracture patients at 9-12 days following fracture may also indicate the increased presence of MSCs in circulation in these patients. There is time-dependent change of caveolin-1 expression during fracture repair: at early stage (13 days after fracture) there is an acute hematoma formation and caveolin-1 expression was low; at 9-12 days following fracture, caveolin-1 expression in PBMNCs was greatly increased and reached its peak and then its expression was reduced at 16-21 days following fracture. The clinical significance of the current study is that it is for the first time we have documented the changes of caveolin- 1 expression during the cases of human long bone fracture healing. The changes of pattern of caveolin-1 expression in PBMNCs may indicate that during normal fracture healing, the acute immune response phase should be within the first 2 weeks, and after that, the repair phase shall follow and caveolin-1 expression shall return to baseline level. If caveolin-1 expression in PBMNCs is prolonged, this may indicate a delayed fracture healing and caveolin-1 expression in PBMNCs may be used as a scanning tool for identifying the patients with potential risk of fracture delayed or non-union at the early stages of fracture (such as at 2 weeks following fracture).

One of the limitations of the current study is that we did not further isolate the subpopulations of cells in the PBMNCs, therefore we were unable to tell which specific cell type is responsible for caveolin-1 gene and protein upregulation. We were unable to examine the caveolin-1 expression in PBMNCs in patients with fracture non-union or delayed union. Nonetheless, the present work forms a foundation for further investigation. The future studies will include the examinations of caveolin-1 expression in the PBMNCs in fracture non-union or delayed patients and to confirm our hypothesis.

In conclusion, we found that human PBMNCs express caveolin-1; the caveolin-1 gene and protein expression in the PBMNCs is increased during the early stages of fracture repair in the patients having long bone fracture in a time dependent manner. The discovery of new signal transduction pathways such as caveolin-1 in PBMNCs may provide an opportunity for understanding the complex interactions that occur between immune responses and repair during fracture repair and may be used as a scanning tool for predicting the risk of fracture delayed or non-union. Additional studies will be necessary to fully evaluate the function of caveolin-1 in circulating PBMNCs in fracture healing process.

Acknowledgments We would like to thank Dr. Denise Shirley and Dr. Peng Huang for their assistance with the collection of blood samples in fracture patients.

\section{References}

1. Anderson RG (1998) The caveolae membrane system. Annu Rev Biochem 67:199-225. doi:10.1146/annurev.biochem.67.1.199

2. Chomczynski P, Sacchi N (1987) Single-step method of RNA isolation by acid guanidinium thiocyanate-phenol-chloroform extraction. Anal Biochem 162:156-159. doi:10.1016/0003-2697 (87) $90021-2$

3. Cilloni D, Vercellino V, Miniero R et al (2000) Bone surgery may act as a stimulus for mobilization of mesenchymal progenitor cells in peripheral blood. Hematologica 85:1-9

4. Dorahy DJ, Lincz LF, Meldrum CJ et al (1996) Biochemical isolation of a membrane microdomain from resting platelets highly enriched in the plasma membrane glycoprotein CD36. Biochem J 319(Pt 1):67-72

5. Fra AM, Williamson E, Simons K et al (1994) Detergent-insoluble glycolipid microdomains in lymphocytes in the absence of caveolae. J Biol Chem 269:30745-30748 
6. Fujimoto T (1993) Calcium pump of the plasma membrane is localized in caveolae. J Cell Biol 120:1147-1157. doi:10.1083/ jcb.120.5.1147

7. Garcia-Cardena G, Martasek P, Masters BS et al (1997) Dissecting the interaction between nitric oxide synthase (NOS) and caveolin. Functional significance of the NOS caveolin binding domain in vivo. J Biol Chem 272:25437-25440. doi:10.1074/jbc.272.41.25437

8. Garcia-Cardena G, Oh P, Liu J et al (1996) Targeting of nitric oxide synthase to endothelial cell caveolae via palmitoylation: implications for nitric oxide signaling. Proc Natl Acad Sci USA 93:6448-6453. doi:10.1073/pnas.93.13.6448

9. Gargalovic P, Dory L (2001) Caveolin-1 and caveolin-2 expression in mouse macrophages. High density lipoprotein 3-stimulated secretion and a lack of significant subcellular co-localization. J Biol Chem 276:26164-26170. doi:10.1074/jbc.M011291200

10. Glenney JR (1992) The sequence of human caveolin reveals identity with VIP21, a component of transport vesicles. FEBS Lett 314:45-48. doi:10.1016/0014-5793(92)81458-X

11. Gorodinsky A, Harris DA (1995) Glycolipid-anchored proteins in neuroblastoma cells form detergent-resistant complexes without caveolin. J Cell Biol 129:619-627. doi:10.1083/jcb.129.3.619

12. Hatanaka M, Maeda T, Ikemoto T et al (1998) Expression of caveolin-1 in human T cell leukemia cell lines. Biochem Biophys Res Commun 253:382-387. doi:10.1006/bbrc. 1998.9744

13. Hillman N, Cox S, Noble AR et al (2001) Increased numbers of caveolae in retinal endothelium and pericytes in hypertensive diabetic rats. Eye 15:319-325

14. Hoffmann JA, Kafatos FC, Janeway CA et al (1999) Phylogenetic perspectives in innate immunity. Science 284:1313-1318. doi:10.1126/science. 284.5418 .1313

15. Kiss AL, Geuze HJ (1997) Caveolae can be alternative endocytotic structures in elicited macrophages. Eur J Cell Biol 73:19-27

16. Lisanti MP, Scherer PE, Vidugiriene J et al (1994) Characterization of caveolin-rich membrane domains isolated from an endothelial-rich source: implications for human disease. J Cell Biol 126:111-126. doi:10.1083/jcb.126.1.111

17. Lisanti MP, Tang ZL, Sargiacomo M (1993) Caveolin forms a hetero-oligomeric protein complex that interacts with an apical GPIlinked protein: implications for the biogenesis of caveolae. J Cell Biol 123:595-604. doi:10.1083/jcb.123.3.595

18. Liu J, Oh P, Horner T et al (1997) Organized endothelial cell surface signal transduction in caveolae distinct from glycosylphosphatidylinositol-anchored protein microdomains. J Biol Chem 272:7211-7222. doi:10.1074/jbc.272.11.7211

19. Liu P, Ying Y, Anderson RG (1997) Platelet-derived growth factor activates mitogen-activated protein kinase in isolated caveolae. Proc Natl Acad Sci USA 94:13666-13670. doi:10.1073/ pnas.94.25.13666

20. Liu P, Ying Y, Ko YG, Anderson RG (1996) Localization of platelet-derived growth factor-stimulated phosphorylation cascade to caveolae. J Biol Chem 271:10299-10303. doi:10.1074/jbc.271. 17.10299

21. Okamoto T, Schlegel A, Scherer PE et al (1998) Caveolins, a family of scaffolding proteins for organizing "preassembled signaling complexes" at the plasma membrane. J Biol Chem 273:54195422. doi:10.1074/jbc.273.10.5419

22. Parolini I, Sargiacomo M, Lisanti MP et al (1996) Signal transduction and glycophosphatidylinositol-linked proteins (lyn, lck, CD4, CD45, G proteins, and CD55) selectively localize in Triton-insoluble plasma membrane domains of human leukemic cell lines and normal granulocytes. Blood 87:3783-3794

23. Parton RG (1996) Caveolae and caveolins. Curr Opin Cell Biol 8:542-548. doi:10.1016/S0955-0674(96)80033-0

24. Repetto S, Bado M, Broda P et al (1999) Increased number of caveolae and caveolin-3 overexpression in Duchenne muscular dystrophy. Biochem Biophys Res Commun 261:547-550. doi:10.1006/bbrc.1999.1055

25. Schnitzer JE, Liu J, Oh P (1995) Endothelial caveolae have the molecular transport machinery for vesicle budding, docking, and fusion including VAMP, NSF, SNAP, annexins, and GTPases. J Biol Chem 270:14399-14404. doi:10.1074/jbc.270.24.14399

26. Schnitzer JE, Oh P, Jacobson BS, Dvorak AM (1995) Caveolae from luminal plasmalemma of rat lung endothelium: microdomains enriched in caveolin, $\mathrm{Ca}(2+)$-ATPase, and inositol trisphosphate receptor. Proc Natl Acad Sci USA 92:1759-1763. doi:10.1073/pnas.92.5.1759

27. Sengelov H, Voldstedlund M, Vinten J et al (1998) Human neutrophils are devoid of the integral membrane protein caveolin. J Leukoc Biol 63:563-566

28. Shaul PW, Smart EJ, Robinson LJ et al (1996) Acylation targets endothelial nitric-oxide synthase to plasmalemmal caveolae. J Biol Chem 271:6518-6522. doi:10.1074/jbc.271.11.6518

29. Solomon KR, Adolphson LD, Wank DA et al (2000) Caveolae in human and murine osteoblasts. J Bone Miner Res 15:2391-2401. doi:10.1359/jbmr.2000.15.12.2391

30. Stahlhut M, Sandvig K, van Deurs B (2000) Caveolae: uniform structures with multiple functions in signaling, cell growth, and cancer. Exp Cell Res 261:111-118. doi:10.1006/excr.2000.4960

31. Werling D, Hope JC, Chaplin P et al (1999) Involvement of caveolae in the uptake of respiratory syncytial virus antigen by dendritic cells. J Leukoc Biol 66:50-58

32. Yan SR, Fumagalli L, Berton G (1996) Activation of SRC family kinases in human neutrophils. Evidence that p58C-FGR and p53/ 56LYN redistributed to a Triton X-100-insoluble cytoskeletal fraction, also enriched in the caveolar protein caveolin, display an enhanced kinase activity. FEBS Lett 380:198-203. doi:10.1016/ 0014-5793(96)00029-4

33. Zvaifler NJ, Marinova-Mutafchieva L, Adams G et al (2000) Mesenchymal precursor cells in the blood of normal individuals. Arthritis Res 2:477-488. doi:10.1186/ar130 